\title{
El duelo por el cuerpo ausente en Secrets in the Sand (2006) de Marjorie Agosín
}

\author{
Miguel López \\ University of New Mexico
}

\author{
La ciudad está descuartizada: \\ cada quien su trozo de violencia
}

(Arminé Arjona, 21)

\begin{abstract}
El tema de los feminicidios en Ciudad Juárez, México, ha generado volúmenes de obras formando un archivo extenso de un cuerpo ausente. Desde finales del milenio y como respuesta a la ola de violencia misógina se ha visto un surgimiento de obras poéticas que forman parte de lo que los editores de Sangre Mía, Poesía de la frontera (2013) denominan como el "debate emocional" de la memoria de las víctimas de este tipo de expresiones de violencia social. Esta producción literaria responde a un período intenso de violencia entre 1993-2001 -en su mayoría contra las mujeres- que reproduce una tipología en la que desaparecen, violan, matan, mutilan y arrojan el cadáver de una mujer en el desierto o en lugares públicos.
\end{abstract}

La producción cultural fronteriza ha retado la capacidad de dimensionar esta tragedia. La película documental Señorita Extraviada (2001) de Lourdes Portillo y obras narrativas como 2666 (2004) de Roberto Bolaño y Sangre en el desierto (2005) de Alicia Gaspar de Alba han llamado la atención internacional al feminicidio. Con la publicación de los poemarios como Mujeres de la brisa (1999) de Joaquín Cosío; Elegía en el desierto (2004) de Micaela Solís; Juárez tan lleno de sol y desolado (2004) de Arminé Arjona; y A tu prójimo amarás (2008) de Carmen Julia Holguín Chaparro, se inicia una intensa producción poética proviniendo por lo general de autores chihuahuenses. La representación de los feminicidios en el nuevo milenio representa una piedra de toque de la realidad mexicana y de la incertidumbre del futuro neoliberal en torno a los derechos humanos. Dentro de este contexto, el poemario bilingüe Secrets in the Sand: The Young Women of Juárez (Secretos en la arena: las jóvenes de Juárez, 2006), de la autora chilena Marjorie Agosín, denuncia la violencia sistémica desde el margen.

Tanto los poemarios individuales como colectivos han abordado las dinámicas de exclusión en este espacio fronterizo. El mutismo de las autoridades, la parsimonia de los órganos judiciales y policiales de un Estado neoliberal en retroceso han ocultado el número real de víctimas. Entre estas el feminicidio es la punta del iceberg de la violencia y la impunidad que llevó las cifras de las víctimas de asesinatos entre bandas del crimen organizado hasta 10.000 entre hombres y mujeres entre el 2006 y 2010.

Con el devenir del Estado neoliberal y la crisis de aplicación de justicia y de protección a la ciudadanía, es el cuerpo precarizado del marginado el 
registro más fehaciente de formas extremas de violencia. Ante esto, las condiciones de actuación de crímenes de lesa humanidad y necroviolencia espectacular nos han Ilevado a redefinir desde la academia su tipología. El término femicide definido por Diane Russell y Jill Radford contempla el "asesinato de una mujer por el hecho de ser mujer" y constituye una forma de terrorismo sexual, ya que es en el cuerpo de la mujer en donde se concentra y agudiza la autoridad y poder de los Estados postdictatoriales (1992). La antropóloga y exdiputada mexicana Marcela Lagarde y de los Ríos ha traducido y adaptado este término como feminicidio: "[p]ara diferenciarlo se eligió la voz feminicidio y denominar así al conjunto de hechos de lesa humanidad que contienen los crímenes y las desapariciones de mujeres" (91). Otros críticos como Sergio González Rodríguez han perfilado este fenómeno como un complejo proceso denominado como una "máquina feminicida" (2004). La tijuanense Sayak Valencia añade un perfil anónimo y estructural a las "muertas de Juárez" y al mecanismo indetenible de su proceso que ella denomina como "capitalismo gore" (2010).

Siguiendo el trabajo de Franz Fanon, el teórico Ramón Grosfoguel propone que el racismo reproduce prácticas en donde los grupos colonizados son considerados por debajo de la categoría de lo humano de acuerdo con sus orígenes culturales, étnicos o de color (10). La racialización -como señala Grosfoguel- ocurre mediante el marcaje de los cuerpos, en que algunos cuerpos son marcados como superiores y otros como inferiores. Los cuerpos definidos como superiores habitan lo que Fanon llama las "zonas del ser" y los inferiores habitan las "zonas del no-ser" (1967).

El presente trabajo analiza la dinámica del cuerpo en torno al feminicidio y las formas de resistencia surgidas de este fenómeno para deslindar los efectos de la violencia estructural representadas en el poemario Secretos en la arena. La representación del espacio juarense como una zona del no-ser en la obra de Agosín plantea diferentes temas y estrategias, con los que Agosín intenta rescatar la memoria de las mujeres y su precarización y desaparición. Primero es el espacio precarizado que la producción capitalista emplea para crear plusvalía y que desplaza al ser humano y sus necesidades. Segundo es el duelo por las víctimas cuyos cuerpos se convierten en fragmentos, huellas, ecos. Estas estrategias hacen que Agosín incorpore a las víctimas de feminicidio fronterizo como una extensión de una guerra sexista, racista y clasista en contra de las mujeres de clase baja y de color del continente, iniciada con los regímenes dictatoriales que azotaron el continente durante la guerra fría.

Una aportación importante de Marjorie Agosín es su lucha contra el silencio y el olvido. El poemario Secretos en la arena constituye la confirmación de una larga carrera de denuncia de violación de derechos humanos y de silenciamiento sistémico en la sociedad latinoamericana desde la dictadura y postdictadura. Agosín es conocida por llamar la atención internacional respecto de las guerras sucias del cono sur, y por examinar la relación entre mujer y memoria en sus obras poéticas, autobiográficas y ensayísticas, entre ellas su poemario Las zonas del dolor (1988), también publicado en formato bilingüe. 
Secretos en la arena representa una forma de luchar por el espacio de la hermandad transfronteriza y de la solidaridad continental. Compuesto por cincuenta y cinco poemas, el poemario se divide en varios núcleos temáticos en donde se distinguen el ambiente del desierto y la pobreza extrema; el cruce de fronteras como forma de avance de las mujeres y respuesta al feminicidio; y el esfuerzo de solidarizarse como forma de habitar los espacios dispersados por la violencia. En sus versos, Agosín utiliza varias perspectivas y voces poéticas para retratar el dolor de la situación y su espacio emotivo pasando del "lugar del no-ser" al "lugar del ser".

Los primeros textos en el poemario señalan la precariedad del ámbito desértico en donde sucede el hallazgo de cadáveres mutilados:

No había en aquellos sitiales

Ni plantas ni rocas.

Solo la muerte desnuda y pérfida.

En aquellos paramos donde las encontraron

Había ciertos ecos llamados vacíos (24)

Así, en esta serie inicial de poemas, Agosín ubica el lugar de las desapariciones y del hallazgo como un espacio precario. El espacio del no-ser es un lugar que niega la existencia; en estos versos, los vocablos "no" y "ni" enfatizan la negación del ser. Como afirma Grosfoguel, la violencia colonial causa la eliminación de posibilidades del colonizado para acceder a una vida mejor y al mismo tiempo le priva de la voz.

El fenómeno de los feminicidios también ha causado una revisión de la función de los medios que han servido en gran medida para acallar esta violencia, como se observa en el siguiente poema:

El noticiero de Ciudad Juárez

Anuncia otra muerte

Parece que es la misma mujer dice el niño

Todas las mujeres esas son iguales responde el padre

La madre desgrana alimentos

Se reconoce en esas mujeres

El noticiero sigue

Anuncian los ganadores del torneo de fútbol

El niño pregunta a su mamá que por qué

Siempre matan a la misma mujer

La madre tiene una voz de extranjera

Una voz de niña

Y se hace un pozo de silencio

En su boca triste (82)

Como nos recuerdan Henry Giroux y Brad Evans, la espectacularización de la violencia en la sociedad contemporánea ha tenido un doble efecto: "The spectacle of violence works by turning human suffering into a spectacle, framing and editing the realities of violence, and in doing so renders some lives meaningful while dismissing others as disposable" (32). 
En el poema citado arriba, la falta de puntuación lo convierte en una sola frase larga que subraya la continua opresión del discurso de los aparatos hegemónicos respecto de la realidad juarense. En el poema se encuentra una tensión entre el niño y el padre como figuras del patriarcado y la madre que se identifica con la mujer muerta. Al calificarlas como "todas iguales", el padre replica el discurso oficial y local masculino que afirma que "esas mujeres" merecen ser castigadas por andar en la calle. El hallazgo de "la muerta" la cosifica y se transforma en el fondo de lo cotidiano, compitiendo por la atención del padre con el partido de fútbol. La frase del niño, "siempre matan a la misma mujer", trivializa la muerte cotidiana. Finalmente, Agosín humaniza a la madre quien lucha contra el silencio con su esfuerzo frustrado de denunciar el terrorismo misógino que nace en el espacio íntimo de la propia casa, empezando con la educación de los hombres.

Secretos en la arena va más allá de representar el dolor de la víctima como una forma perdida y ve en la vida de las mujeres una forma de resistir el ámbito opresivo que las circunda. En efecto, una forma de intervenir y contrarrestar la carencia de voces y silencio que pesa sobre el feminicidio consiste en crear estados de emoción en los que el lector se pueda identificar. Uno de los poemas centrales de la antología trata lo que Agosín llama la "Huerfanía" que es el estado de indefensión y desesperación en que caen las familias de las asesinadas.

Ante la añoranza

Era el secreto recinto del silencio

Huía de las voces ajenas

Elegí la huerfanía

El contorno de todo lo sumergido

Busqué la voz

En lo que no se oye (26)

Aquí la voz poética nos transporta a otros ámbitos en donde el neologismo "huerfanía" contribuye a repensar las múltiples aristas de la pérdida y el desamparo. La palabra "huerfanía" singulariza y especifica la voz de la máquina juarense en donde ni el eco existe y en donde el lenguaje no es suficiente para dimensionar la tragedia que Agosín intenta nombrar. Nombrar es parte del proceso de desmitificación del poder; en este sentido Agosín coincide con activistas locales al intentar dar explicaciones creíbles a la violencia y retar la mitificación de la misma que se ve en las versiones mediáticas y oficiales.

Cuando los cuerpos de algunas de las mujeres no son encontrados, la memoria de las desaparecidas se convierte en bandera de lucha que hermana a las Madres de la Plaza de Mayo, las desaparecidas de Guatemala y las de Ciudad Juárez. Michael Lazzara nos recuerda que: "Allí donde no hay cuerpos, donde no hay pruebas materiales de la muerte, donde no hay cierre para los familiares, los desaparecidos se mantienen en una suerte de limbo entre la vida y la muerte, como espectros vagando entre los vivos, esperando ser oídos, reconocidos y recordados" (164). En su prosa poética, Agosín reanima la memoria de las desaparecidas: 
Y de pronto la ciudad se convirtió en una sola luz en una sola mirada en una sola historia. Las voces eran rugidos, murmullos, como un terciopelo desgarrado, y eran voces claras como los espejos del agua y eran voces que no dejaban de preguntar y susurrar y llamaban en el idioma del amor y llamaban en el idioma de la memoria (36).

El tema del combate en contra del silencio y el olvido une los poemas de la colección. En este pasaje, Agosín se convierte en testigo de la historia y por ello en una voz que no se deja callar. La ciudad se representa como un lugar desde donde de la clase obrera puede recobrar y articular su historia borrada y ocultada por el colonialismo y el racismo del mundo industrializado.

Con Secretos en la arena, Agosín aporta varios poemas en pro del futuro esperanzador. Agosín elabora en el rol determinante de las mujeres en cambiar el rumbo de la historia. Las mujeres asesinadas cruzan fronteras y habitan en el umbral del futuro. En el poema, la frontera, el borde, el espacio nacional limitante es desbordado por las laboriosas mujeres que son asesinadas y suspendidas en el mundo fronterizo fantasmal. Como en sus poemarios acerca de las desapariciones en Chile bajo Pinochet, Las zonas del dolor y Lluvia en el desierto aquí los espíritus nos toman de la mano y nos guían hacia un futuro incierto:

Y ella cruzaba fronteras

Avanzaba

Giraba

Era osada en sus ires

$Y$ venires

Llevaba cántaros de agua

Esperanza del color de agua.

Ella cruzaba fronteras,

$Y$ en todas ellas,

La detenían,

La acusaban,

La revisaban

Como si fuera un ave malhechora.

Insaciable,

Determinada,

Feliz,

Ella cruzaba fronteras

Su cuerpo era un umbral

Donde el norte y el sur

Eran palabras claras

Para lavar la mirada

El corazón

Pulir las grietas (38). 
En este poema Agosín ofrece una elegía a las mujeres que han sido asesinadas y señala su valor en la lucha por el derecho de las mujeres de buscar su lugar en el mundo del futuro. Su trabajo es "unir el norte y el sur", una doble operación cuyo objetivo es la permanencia en la memoria de las mujeres violentadas y ausentes.

Los poemas de esta colección giran en torno al tránsito y al movimiento de las mujeres en búsqueda de mejores y mayores espacios en la sociedad fronteriza frente a los sueños interrumpidos. Por medio de una tenaz lucha por los derechos humanos de los desposeídos, marginales e invisibles del "progreso" neoliberal, Marjorie Agosín se ha distinguido por innovar formas poéticas combatiendo el silencio histórico que se les ha impuesto. De manera similar a la que había empleado en el contexto chileno en Las zonas del dolor, Lluvia en el desierto y en Secretos en la arena, la poeta presta su voz para construir un espacio emotivo en el marco del México neoliberal para impedir el silenciamiento del complejo fenómeno del feminicidio.

\section{Obras citadas}

Agosín, Marjorie. Secrets in the Sand/ Secretos en la arena. Trans. Celeste Kostopulos Cooperman. Buffalo NY: White Pine Press, 2006. Print. Zones of Pain/Zonas del dolor. Trans. Franzen Cola. Buffalo NY: White Pine Press, 1999. Print.

Lluvia en el desierto/Rain in the Desert. Santa Fe, NM: Trans. Sherman Asher, 1999.

Arjona, Arminé. Juárez tan lleno de sol y desolado. Delicias, Chihuahua: Chihuahua Arde (2004). Print.

Bolaño, Roberto. 2666. Barcelona: Anagrama, 2004.

Cosio, Joaquín. "Mujeres de la brisa". Cinco poetas del norte. Ciudad de México: UNAM, 1999. Print.

González Rodríguez, Sergio. Femicide Machine. Cambridge MA: MIT Press, 2008. Print.

Gaspar de Alba, Alicia. Desert Blood Houston: Arte Público Press, 2005.

Giroux, Henry y Brad Evans. Disposable Futures: The Seduction of Violence in the Age of Spectacle. San Francisco: City Lights Open Media, 2015.

Grosfoguel, Ramón. "What is Racism?". Journal of World Systems Research. 22: 1 (2016): 9-15.pp https://jwsr.pitt.edu/ojs/index.php/jwsr/article/ view/609. Acceso January 30, 2019.

Holguín-Chaparro, Carmen Julia. A tu prójimo amarás. México: UNAM, 2008.

Lagarde y de los Ríos, Marcela. Del femicidio al feminicidio. En: Desde el jardín de Freud. Bogotá: Universidad Nacional de Colombia, 2006. Print. https://revistas.unal.edu.co/index.php/jardin/article/view/8343/8987. Acceso enero 30, 2019.

Lazzara, Michael. Prismas de la memoria: Narración y trauma en la transición chilena, Chile Santiago de Chile: Cuarto Propio, 2007.

Portillo, Lourdes. Señorita Extraviada. New York: Women Make Movies, 2001.

Rathbund, Jenifer y Juan Armando Rojas Joo. Sangre Mía, Poesía de la frontera.

Ohio Wesleyan University/NMSU/Center for Latin American and Border Studies: Las Cruces New Mexico, 2013.

Russell, Dianne y Jill Radford. Femicide: the Politics of Women Killing. New York: Maxwell-McMillan International, 1992.

Solís, Micaela. Elegía en el desierto: in memoriam. Ciudad Juárez: UACJ, 2004.

Valencia, Sayak. Capitalismo Gore. Barcelona: Melusina, 2018. 